\title{
Strategi Penyajian Konten di Instagram LLDikti Wilayah III dalam Menginformasikan Program MBKM
}

\author{
Alexandra Virginia Miharja ${ }^{1}$, Moehammad Gafar Yoedtadi ${ }^{2}$ \\ ${ }^{1}$ Fakultas Ilmu Komunikasi, Universitas Tarumanagara, Jakarta \\ Email: virginialexandra18@gmail.com \\ ${ }^{2}$ Fakultas Ilmu Komunikasi, Universitas Tarumanagara, Jakarta* \\ Email: gafary@fikom.untar.ac.id
}

Masuk tanggal: 15-12-2021, revisi tanggal: 06-01-2022, diterima untuk diterbitkan tanggal: 16-01-2022

\begin{abstract}
In the effort to provides Indonesia's education to be more advance, The Ministry of Education, Culture, Research, and Technology have a new program called 'Merdeka Belajar Kampus Merdeka (MBKM)'. The program is an initial step for academics especially Indonesian student to have a chance to increase their skills in terms of talent and interest. The purpose of this research is to examine the strategy of publishing content by LLDikti Region III in Instagram platform to inform MBKM program. The theory that used in the research is Management Strategy and New Media Theory in government institution. This research use qualitative approach with case study method. The case study is being used on LLDikti Region III Instagram @humas.lldikti3. Data collection performed with interview with PR institution and publication chief in LLDikti Region III also by observation through video call with Zoom application. The result of this research is the strategy that being used by LLDikti Region III in Instagram is already based on planning and evaluation of strategies.
\end{abstract}

Keywords: content strategy, Instagram, mass communication, Merdeka Belajar Kampus Merdeka, new media

\begin{abstract}
Abstrak
Dalam upaya memajukan pendidikan di Indonesia supaya menjadi lebih unggul, Kementerian Pendidikan, Kebudayaan, Riset, dan Teknologi (Kemdikbudristek) mengeluarkan kebijakan baru berupa Program Merdeka Belajar Kampus Merdeka (MKBM). Program tersebut merupakan langkah awal bagi para akademisi khususnya pelajar di Indonesia agar mendapatkan kesempatan untuk mengasah kemampuannya dari segi bakat dan minat. Penelitian ini bertujuan untuk meneliti strategi yang telah dibentuk oleh pihak LLDikti Wilayah III untuk memperluas Program Merdeka Belajar Kampus Merdeka (MBKM). Rumusan masalah yang terdapat dalam penelitian ini adalah untuk mengetahui strategi penyajian konten di Instagram LLDikti Wilayah III dalam menginformasikan Program MBKM. Teori yang digunakan pada penelitian ini adalah teori strategi manajemen dan teori media baru (media sosial di pemerintahan). Penelitian ini menggunakan pendekatan kualitatif dengan metode studi kasus. Studi kasus dilakukan pada Instagram LLDikti Wilayah III @humas.lldikti3. Pengumpulan data dilakukan dengan teknik wawancara kepada Pranata Humas dan Penyusun Bahan Publikasi LLDikti Wilayah III serta melakukan observasi melalui video call di aplikasi Zoom. Hasil dari penelitian ini menunjukkan bahwa strategi penyajian konten yang dilakukan oleh LLDikti Wilayah III di Instagram telah berdasarkan perencanaan dan evaluasi dari strategi yang telah ditetapkan.
\end{abstract}

Kata Kunci: Instagram, komunikasi massa, media baru, Merdeka Belajar Kampus Merdeka, strategi konten 


\section{Pendahuluan}

Dalam masa pandemi, masyarakat mendapatkan informasi dengan cara yang mudah berbagai media. Informasi yang diperoleh didapatkan dari komunikator kepada komunikan baik secara langsung maupun tidak langsung. Kemudahan akses penerimaan informasi disebabkan adanya penggunaan saluran dari jenis media yang tersedia. Penelitian ini memiliki kaitan dengan jenis media pencarian informasi (Dennis McQuail, 2011).

Menurut Fortunati (2016) dalam buku yang berjudul "Teori Komunikasi Massa" oleh McQuail, media baru dibedakan dari berbagai perspektif pengguna. Penjelasan kekayaan media (media richness) mengenai jangkauan suatu media dapat memberikan pandangan yang berbeda dapat diartikan sebagai langkah awal dalam penyampaian informasi.

Instagram merupakan salah satu media sosial yang berhasil mencapai kesuksesan dari segi pengguna kalangan muda maupun ke kalangan yang sudah berumur. Aplikasi ini diluncurkan pada tanggal 06 Oktober 2010 yang awalnya dibuat khusus hanya untuk pengguna iOS. Namun, perusahaan telah mengupayakan pelebaran jangkauan penggunanya dengan merilis Instagram for Android pada bulan April tahun 2012. Di negara Indonesia, jumlah pengguna aktif Instagram hingga bulan Juni 2021 sebanyak 91,77 juta, dengan rincian pengguna terbesar berada di kelompok usia 18-24 tahun dengan persentase 36,4\% (Rizaty, 2021). Dari data tersebut, Konteks penelitian yang dilakukan oleh peneliti akan didasari oleh penyajian konten Instagram LLDikti Wilayah III.

Lembaga Layanan Pendidikan Tinggi (LLDikti) Wilayah III merupakan unit kerja Kementerian Pendidikan, Kebudayaan, Riset, dan Teknologi Republik Indonesia yang berada di Provinsi D.K.I Jakarta, berdasarkan laman online LLDikti Wilayah III memiliki beberapa jabatan atau divisi untuk menjalankan tugas serta melaksanakan fasilitasi peningkatan mutu penyelenggaraan pendidikan tinggi di wilayah kerjanya.

Sebagai Lembaga yang berada di bawah naungan Kementerian Pendidikan, Kebudayaan, Riset, dan Teknologi Republik Indonesia, LLDikti memiliki beberapa program dalam hal penyelenggaraan dan mutu perguruan tinggi untuk mendiseminasikan suatu kebijakan. Salah sat kebijakan itu adalah program Merdeka Belajar Kampus Merdeka (MBKM).

Berdasarkan situs online resmi dari Kampus Merdeka, kebijakan Merdeka Belajar oleh Kementerian Pendidikan, Kebudayaan, Riset, dan Teknologi Republik Indonesia bertujuan untuk memberikan kesempatan bagi mahasiswa dan mahasiswi untuk mengasah kemampuan sesuai bakat dan minat individu dengan cara terjun langsung ke dunia kerja sebagai persiapan karier masa depan.

Meskipun sosialisasi yang dilakukan oleh Kemdikbudristek dalam menginformasikan program MBKM dinilai unggul, pihak LLDikti Wilayah III turut ambil bagian melalui pengemasan konten yang disebar melalui akun Instagram (@humas.lldikti3). Oleh karena itu, peneliti tertarik untuk membuat penelitian mengenai Strategi Penyajian Konten Instagram LLDikti Wilayah III Dalam Menginformasikan Program MBKM. 


\section{Metode Penelitian}

Penelitian ini dilakukan dengan metode penelitian kualitatif deskriptif. Penelitian kualitatif deskriptif yang akan dilakukan bertujuan untuk menjawab pertanyaan yang berhubungan dengan objek penelitian yang nantinya akan dilakukan (Barlian, 2016). Berkaitan dengan strategi penyajian konten di Instagram, pendekatan penelitian secara kualitatif deskriptif cocok untuk dijadikan acuan karena menginformasikan keadaan yang sesuai dengan realita, dalam hal ini keadaan Instagram LLDikti Wilayah III.

Studi kasus pada penelitian ini dilakukan dengan mengamati penyajian konten di Instagram yang telah dibentuk oleh Tim Humas LLDikti Wilayah III terkait Program Merdeka Belajar Kampus Merdeka. Subjek dalam penelitian ini adalah anggota dari Humas LLDikti Wilayah III yaitu Pranata Humas dan Penyusun Bahan Publikasi. Objek dalam penelitian ini adalah strategi yang dibentuk untuk penyajian konten MBKM di Instagram LLDikti Wilayah III.

Sumber data primer peneliti adalah wawancara mendalam dengan narasumber dari Pranata Humas LLDikti Wilayah III, Dhita Widya Putri dan Sigit Nugroho selaku Penyusun Bahan Publikasi di Humas LLDikti Wilayah III. Penelitian ini menggunakan sumber data sekunder seperti jurnal, artikel, dokumen, dan informasi yang sebagian nya diperoleh dari pihak yang berkaitan dengan strategi penyajian konten di Instagram LLDikti Wilayah III.

Pemilihan informan tersebut telah memenuhi kualitas kriteria informan (goodness criteria). Menurut Kriyantono, pemilihan narasumber ataupun informan harus dilihat dari kompetensinya terhadap bidang yang dituju (dalam penelitian ini adalah strategi penyajian konten). Selain itu, adanya konfirmasi dari hasil wawancara tersebut yang dibuktikan dengan kesesuaian data yang diperoleh dari penelitian (Kriyantono, 2014).

Untuk memperoleh kredibilitas yang tinggi, metode triangulasi berguna untuk menggabungkan berbagai teknik pengumpulan data dan sumber data yang telah diperoleh. Menurut Stainback dalam Hardani et al., (2020) menyatakan bahwa tujuan dari triangulasi bukan hanya mencari kebenaran dari suatu kasus yang diangkat, tetapi juga pada memberikan pemahaman lebih kepada peneliti terhadap kejadian yang diperoleh.

\section{Hasil Temuan dan Diskusi}

Demi tercapainya peningkatan kemampuan para akademisi di perguruan tinggi, tim humas LLDikti Wilayah memiliki peran dalam hal menginformasikan program serta kebijakan Kemendikbudristek MBKM. Sehingga ini akan membantu Perguruan Tinggi memiliki akreditasi unggul dan menghasilkan lulusan yang berkualitas.

Kegiatan publikasi di media sosial Instagram telah dilakukan oleh LLDikti Wilayah III dengan cara mengumpulkan, mengolah, dan mempublikasikan informasi mengenai kebijakan/Program Merdeka Belajar Kampus Merdeka yang berasal dari satuan lingkup kerja Kemdikbudristek. Berbicara tentang strategi menyajikan konten di Instagram LLDikti Wilayah III, Kurniasih (2013) menyatakan bahwa pemerintah menggunakan media sosial untuk berbagai kepentingan, namun yang paling mendasar ialah menjaga serta meningkatkan reputasi dari suatu lembaga serta 
menggali seluruh aspirasi publik yang pada masa sebelum dilakukannya optimalisasi media sosial tidak tersalurkan (Kurniasih, 2013).

Strategi yang diperlu diperhatikan dalam lembaga pemerintahan adalah menentukan pesan utama yang nantinya bertujuan untuk pembuatan konten serta mengimplementasikan strategi-strategi yang sudah diatur sedemikian rupa (Meiningsih, 2018). Sehingga dalam menunjang pemahaman tersebut diperlukan komponen pendukung untuk menjelaskan berbagai strategi yang telah dibentuk, yakni:

\section{Plan and Strategy}

Tim Humas LLDikti Wilayah III dalam menyajikan konten MBKM di Instagram selalu mengadakan rapat untuk membahas tema dan pembuatan konten media sosial yang bersumber dari laman/website LLDikti Wilayah III, dokumen (berupa file) pemberitaan dari perguruan tinggi di lingkungan LLDikti Wilayah III yang telah dikumpulkan melalui Google Drive, serta dari berbagai koordinasi bagian (sumber daya perguruan tinggi, akademik, kemahasiswaan, kelembagaan dan sistem informasi). Konten-konten yang dimuat haruslah memenuhi 5-able: findable, readable, understandable, actionable, dan shareable.

Berdasarkan konten di Instagram LLDikti Wilayah III dalam menginformasikan Program Merdeka Belajar Kampus Merdeka, dibuktikan dengan pembuatan konten di Instagram yang selalu membubuhkan 3 logo dalam setiap postingan, yakni LLDikti Wilayah III dengan ornamen khas D.K.I Jakarta-nya (kebetawian), Zona Integritas, dan Kampus Merdeka. Namun terdapat tambahan icon ondel-ondel yang ditempatkan untuk frame konten repost.

Setelah perencanaan konten dikemas, tim humas akan membaginya berdasarkan peran kerja, untuk desainer grafis memproses secara visual dan admin media sosial untuk proses pengunggahan konten serta layanan informasi.

"Setiap bulan kami buat konten kalender. Bertujuan untuk menentukan tema baru setiap bulannya, misalkan bulan ini adalah bulan penuh semangat, kemudian bulan depan itu bulan penuh motivasi. Jadi setiap bulan kami sudah menentukan isi tema dan jadwal publish di hari apa. Biasanya kami mengunggah tentang hari-hari besar, lalu informasi-informasi penting atau apresiasi terhadap perguruan tinggi." - Dhita.

\section{Action}

Dari setiap unggahan konten di Instagram LLDikti Wilayah III, Tim Humas LLDikti Wilayah III berusaha untuk selalu memberikan informasi yang jelas, baik konten yang diproduksi sendiri ataupun yang di-repost dengan tujuan untuk mengedukasi penikmat konten. Oleh karena itu, LLDikti Wilayah III lebih menekankan kepada kebutuhan akademis, serta menunjukan outcome dari programprogram yang ada.

LLDikti Wilayah III juga menciptakan kolaborasi dengan perguruan tinggi atau influencers dengan melakukan co-creation content sebagai langkah kerjasama yang nyata, yaitu dalam bentuk digital event and exhibition. Selain itu LLDikti Wilayah III juga menyelenggarakan forum kehumasan, Bimtek, dan diskusi bersama para pakar di industri serta humas di setiap Perguruan Tinggi untuk mendapatkan insight yang berguna demi pengembangan konten dan menambah pengetahuan. 
Dengan penentuan Instagram menjadi kanal utamanya, hal ini dimaksudkan agar Tim Humas LLDikti Wilayah III fokus pada audiens yang dimiliki, sehingga adanya penetapan sasaran (target audiens) dalam memberikan panduan MBKM kepada kampus-kampus yang berada di lingkungan LLDikti Wilayah III.

Di masa sekarang ini, LLDikti Wilayah III terus berupaya untuk mengikuti perkembangan zaman yang semakin maju, salah satunya dengan menerapkan beberapa kategori utama dari media baru yang dipaparkan oleh Rice (2016) dalam Dennis McQuail (2011) yakni:

a. Media partisipasi kolektif (collective participatory media).

Penggunaan internet oleh LLDikti Wilayah III bertujuan untuk berbagi dan bertukar informasi, gagasan, dan pengalaman, serta untuk mengembangkan hubungan pribadi aktif. Terbukti dengan adanya website untuk memudahkan penyebaran informasi secara general, kolom komentar yang bertujuan untuk berinteraksi dengan pengikut di Instagram, dan penggunaan platform lain sebagai tanda mengikuti arus perkembangan teknologi saat ini. Seiring dengan bertumbuh kembangnya media komunikasi saat ini, LLDikti Wilayah III berencana meluncurkan Potensi Kita (Podcast LLDikti Wilayah III Jakarta) dan mengintegrasikan berbagai konten media sosial.

"Sekarang kita lagi cek ombak aja nih kebetulan kita udah ada satu episode perdana kita pengen tahu animonya orang-orang tuh gimana sih dalam mendengarkan podcast gitu ya kalau pas ke situ, ini kan modelnya satu media untuk semua jadi dari satu kali konten itu bisa disebar di mana-mana gitu loh." - Dhita.

b. Substitusi media penyiaran (substitution of broadcasting media).

LLDikti Wilayah III memiliki acuan utama pada penggunaan media untuk menerima atau mengunduh konten yang terdapat di masa lalu yang biasanya disiarkan atau disebarkan dengan metode lain yang serupa. Dalam hal ini, LLDikti Wilayah III mengunduh ulang hasil diskusi dari live Instagram ke feeds Instagram.

"Bahkan kita juga mengikuti perkembangan zaman gitu ya dengan adanya perkembangan konsumsi media jadi kita masuk ke ranah YouTube, kita masuk kanal live Instagram gitu." - Nugroho.

\section{Evaluations}

Berdasarkan Permendikbud No.34 Tahun 2020, LLDikti Wilayah III berfungsi dalam hal fasilitasi layanan, data dan informasi, pemetaan, monitoring, evaluasi, dan pelaporan demi mengingkatkan mutu Perguruan Tinggi. Sehingga strategi yang menjadi bahan pertimbangan untuk menyebarkan informasi adalah Strategi Fungsional (functional strategy), hal ini dibuktikan dengan LLDikti Wilayah III memiliki tujuan untuk mendapatkan cara terbaik dalam mencapai target/sasaran (hal ini adalah Program Merdeka Belajar Kampus Merdeka) melalui produktivitas pekerja (Tim Humas LLDikti Wilayah III).

Pada awal tahun 2021, LLDikti Wilayah III melakukan survei. Hasilnya, sebagian besar pengikut Instagram LLDikti Wilayah III berusia 26-40 tahun, yaitu generasi milenial yang termasuk kedalam kategori umur produktif dan aktif bermedia 
sosial. Hal ini juga didukung dengan temuan bahwa kalangan mahasiswa dan dosen muda mendominasi sebagai penikmat konten.

Hasil dari penetapan target audiens dan rapat evaluasi kinerja media sosial LLDikti Wilayah III adalah mencoba menetapkan strategi baru, yakni dengan mempublikasikan berbagai informasi dan kebijakan dengan dengan model serta gaya bahasa yang berbeda ke setiap media sosial yang kami miliki.

Dari hasil wawancara yang telah dilakukan, beberapa hal yang telah dijalankan oleh Tim Humas LLDikti Wilayah III adalah menetapkan Instagram sebagai media utama. Hal ini bertujuan untuk menggarap minat kalangan milenial di bawah naungannya, dengan harapan agar mengetahui dengan baik dari salah satu program yang dijalankan oleh Kemdikbudristek, yakni Merdeka Belajar Kampus Merdeka. Penetapan target audiens di Instagram bertujuan untuk membantu LLDikti Wilayah III dalam menempatkan sumber daya yang diperolehnya. Jadi, Humas LLDikti Wilayah III dapat menjalankan tugasnya untuk menyebarkan informasi seputar Merdeka Belajar Kampus Merdeka. LLDikti Wilayah III telah menetapkan standar yang tinggi dan juga konsisten dengan segala pencapaian atau prestasi dan juga dari pengemasan kontennya yang dihasilkan untuk membangun citra baik dan budaya perusahaan yang khas, sehingga dapat dikenal oleh khalayak luas. Dengan dilakukannya penetapan sasaran tersebut, diharapkan dapat membantu Humas LLDikti Wilayah III untuk menilai kinerjanya sendiri. Hal tersebut dilakukan dengan cara melakukan evaluasi/record atau hasil dari pencapaian yang telah dijalankan.

Dari setiap program yang memenuhi strategi yang diformulasikan sehingga bisa berdampak positif tidak membuat Tim Humas LLDikti Wilayah III cepat puas. Berbagai upaya seperti trial and error, tindak lanjut dari strategi dan taktik yang berasal dari hasil data analytics terus menjadi bahan untuk perbaikan.

\section{Simpulan}

Strategi Penyajian konten di Instagram LLDikti Wilayah III Dalam Menginformasikan Program Merdeka Belajar Kampus Merdeka (MBKM) mengacu kepada Peraturan Menteri Pendidikan dan Kebudayaan Republik Indonesia No. 34 Tahun 2020 tentang Organisasi dan Tata Kerja Lembaga Layanan Pendidikan Tinggi. Dalam menjalankan tugasnya, Tim Humas LLDikti Wilayah III termasuk ke dalam kelompok jabatan fungsional yang tentu menerapkan strategi fungsional dalam proses menyusun dan mengembangkan program atau kegiatan pembuatan konten Merdeka Belajar Kampus Merdeka. Penerapan teori media baru yang dilakukan oleh LLDikti Wilayah III termasuk ke dalam kategori media partisipasi kolektif (collective participatory media) dan substitusi media penyiaran (substitution of broadcasting media). Namun di komponen strategi media sosial dalam lembaga pemerintahan yang terdiri dari karakter, tujuan utama, motif utama, cerita utama, dan rincian, komponen rincian belum sepenuhnya dijalankan oleh Humas LLDikti Wilayah III. Penyajian konten yang terdapat di Instagram LLDikti Wilayah III kurang begitu banyak menyebarkan secara mendalam paparan Program MBKM dan dari konten yang dihasilkan terdapat pemahaman yang sulit dimengerti dan tidak mendetail. 


\section{Ucapan Terima Kasih}

Peneliti ingin mengucapkan terima kasih kepada Fakultas Ilmu Komunikasi Universitas Tarumanagara, narasumber, serta semua pihak yang turut membantu peneliti sehingga penelitian ini dapat diselesaikan.

\section{Daftar Pustaka}

Barlian, E. (2016). Metodologi Penelitian Kualitatif \& Kuantitatif. Penerbit Sukabina Press.

Fortunati, L. (2016). Mediatization of the Net and Internetization of the Mass Media: Http://Dx.Doi.Org/10.1177/0016549205049177, 67(1), 27-44. https://doi.org/10.1177/0016549205049177

Hardani, Auliya, H. N., Andriani, H., Fardani, A. R., Ustiawaty, J., Utami, F. E., Sukmana, J. D., \& Istiqomah, R. R. (2020). Metode Penelitian Kualitatif dan Kuantitatif (H. Abadi (Ed.)). CV. Pustaka Ilmu Group. https://www.researchgate.net/publication/340021548

Kriyantono, R. (2014). Kualitas Penelitian Kualitatif - Goodness Criteria. http://rachmatkriyantono.lecture.ub.ac.id/files/2014/10/KUALITASPENELITIAN-KUALITATIF.pdf

Kurniasih, N. (2013). Penggunaan Media Sosial bagi Humas di Lembaga Pemerintah. Forum Kehumasan Kota Tangerang, September, 1-22. https://doi.org/10.13140/RG.2.2.15820.41609

McQuail, Dennis. (2011). Teori Komunikasi Massa McQuail Edisi Buku Denis McQuail.

Meiningsih, S. (2018). Memaksimalkan Penggunaan Media Sosial dalam Lembaga Pemerintahan (1st ed.). Direktorat Jenderal Informasi dan Komunikasi Publik, Kementerian Komunikasi dan Informatika.

Rice, R. E. (2016). Artifacts and Paradoxes in New Media: Http://Dx.Doi.Org/10.1177/1461444899001001005, $1(1), \quad$ 24-32. https://doi.org/10.1177/1461444899001001005

Rizaty, A. M. (2021, August 3). Inilah Negara Pengguna Instagram Terbanyak, Indonesia Urutan Berapa? Databoks. https://databoks.katadata.co.id/datapublish/2021/08/03/inilah-negarapengguna-instagram-terbanyak-indonesia-urutan-berapa 